\title{
Report
}

\section{Belief in Just World as a Predictor of Psychological Problems Among Hermaphrodites in Pakistan}

\author{
Shahida Sadiq ${ }^{1}$, Aneeza Bashir ${ }^{2}$ \\ ${ }^{1}$ Department of Psychology, Govt. Postgraduate College (W) M. B. Din, Mandi-Bahaudin, Pakistan \\ ${ }^{2}$ Department of Psychology, University of Sargodha, Sargodha, Pakistan
}

Email address:

shahidasadiq22@gmail.com (S. Sadiq),aneeza16@gmail.com (A. Bashir)

\section{To cite this article:}

Shahida Sadiq, Aneeza Bashir. Belief in Just World as a Predictor of Psychological Problems Among Hermaphrodites in Pakistan. Psychology and Behavioral Sciences. Vol. 9, No. 4, 2020, pp. 50-55. doi: 10.11648/j.pbs.20200904.13

Received: July 3, 2020; Accepted: July 23, 2020; Published: August 19, 2020

\begin{abstract}
This study examines belief in just world as a predictor of psychological problems among hermaphrodites in Pakistan. A total of 153 hermaphrodites $(n=132$, junior members of community, $n=21$, senior members of community) were recruited through community-based organizations and referrals by snowball sampling technique. Personal BJW was measured by (Personal BJW Scale: developed by Dalbert and translated by Fatima \& Khalid), general BJW by (Scales of Belief in Immanent and Ultimate Justice: developed by Maes and translated by Fatima \& Suhail) and presence of feelings of depression, anxiety and stress by (DASS: Lovibond \& Lovibond, translated by Aslam). Pearson correlation, step-wise regression was employed to analyze the relationship between Belief in Just World and psychological troubles. Significant results were found that high general Belief in Just World leads to increased risk of psychological problems and personal BJW decrease the level of depression, anxiety, and stress (psychological problems). The findings are helpful for therapeutic exercise as part of ongoing personal and general BJW growth they should be encouraged to readjust other aspects of lifespan as they see fit. Clinician can identify hermaphrodites' problems and find out different ways that contribute to better adjusted in society and help them to use inner strength using personal and general BJW to come out of these psychological problems.
\end{abstract}

Keywords: Personal Belief in Just World, General Belief in Just World, Depression, Anxiety \& Stress

\section{Introduction}

Just world assumption illustrated that human being has to think that they live in a world where people generally deserve what they get and get what they deserve. The belief in a just world provides important adaptive functions and facilitates the person to deal with his corporeal and social surroundings as though they were constant and ordered. Belief in a just world provides a sort of coping system to make possible for people to have a thinking of well-being, thus fallaciously defending them from harms. The concept of belief in just further divided into personal BJW which play adaptive function and reduced level of psychological problem as compared with general BJW.

\subsection{Belief in a Just World}

Belief in Just World hypothesis describe that, worthily and innately, if a person does good things, good things will happen to them and if bad, bad things do will happen to them. People have prejudiced observation of world fairness of self and other [1]. Dalbert argued that a difference should be made between the beliefs in a just world for himself/ herself and the general BJW [2]. The BJW for self is related to the belief of an individual that on average events of his/her personal life is fair, while general BJW reveals the belief that on the whole, this world is a fair point [3]. Dzuka and Dalbert argued that people try to support personnel BJW stronger than general BJW and therefore personal belief in a just world is a better interpreter of their reactions to justice-related issues $[4,5]$.

\subsection{Depression}

Depression inwardly affects the mental health by causing traumatic experiences. Depression is the sensitivity towards 
dysphoria, worthlessness, self-criticism, devaluation of life, apathy, anhedonia, and lack of attention [6]. American Psychiatric Association describes the symptoms that can be consistently observed in depression including feelings of worthlessness, loss of pleasure in all or almost all activities, fatigue, diminished ability to think or focus, and feelings of hopelessness, loss of energy [7].

\subsection{Anxiety}

Anxiety is a psychological condition characterized by behavioral, emotional, cognitive and somatic components. These mechanisms come together to generate a distasteful emotion that is naturally related to restlessness, panic and agonized response [8]. Anxiety is a widespread frame of mental state that takes place devoid of certain activating incentive and is different from fear, which occurs in an event of an experiential danger and is also associated with explicit actions of the flight and prevention, whereas anxiety is the consequence of the terrorization that is supposed to be inevitable [9]. According to Barlow and David anxiety is related to future frame of mind situation in which one is prepared to attempt to deal with future related harmful proceedings when anxious response occurs in disproportion to the nature of anxiety-provoking stimuli and interfere with everyday functioning, they become devastating and can no longer be considered normal and adaptive $[10,11]$.

\subsection{Stress}

Stress is a chronic, general arousal, feeling troubled in relaxing, being agitated without difficulty and tense stimulation, touchy and intolerant [6]. Stress arises when someone recognizes that ecological difficulties have surpassed his/her adaptation abilities. Stressful actions are considered to effect psychologically by producing a harmful emotional condition which applies direct sound effects on behavioral activities [12]. Experience of stress is thought as the most harmful because stress causes changes in the physiological, emotional and behavioral reactions that affect vulnerability to the course of illness [13]. It was also found that experience to more than three stressful life events was associated with variation in levels of anxiety and depression [14].

\subsection{BJW and Psychological Problems}

Ritter, Benson, and Snyder described that there is a significant negative association between belief in a just world and depressive symptoms [15]. Schmitt and Maes revealed that there is a negative association between depression and a general belief in just world [16]. Comparative study on the mental distress of police officers showing high and/or low level of stress showed that participants who exposed high level of belief in just world, have lower levels of mental distress than those participants who have low levels of belief in just world [17]. Same results with regard to stress and belief in just world were also revealed by studies on the subgroup of the same sample. Dalbert conducted studies on sample of jobless women, mothers of a immobilize kid and scholars, the results suggested that those participants who have a high belief in just world they were in good effective state, they are contented with their lives and they experience less problematic situations as compared with participants who are low on BJW [18].

In another study, Dalbert concluded that BJW was significantly positively correlated with life satisfaction and mood level and negatively correlated with feelings of stress [16]. A positive relationship was found between BJW and well being and a negative correlation was found between belief in just world and depression [19].

A further study conducted to measure the association between BJW and mental fitness indicates that there is an affirmative relationship between the conservative orientation of belief in just world and hopelessness among students [20]. Two studies concluded that there were a cause and effect relation between belief in just world and well-being [21, 22]. Comparative researchers described that role of $\mathrm{BJW}$ is more prominent in the improvement of well being and decreasing negative effect in participants those who experience unfavorable conditions that are harmful to a person.

Lipkus, Dalbert and Siegler Distinguished BJW into personal BJW and general BJW and demonstrated that personal BJW was more related to a positive construct like well-being than general BJW [23]. Dalbert described that personal belief in just world has a positive relationship with mental wellbeing [2]. A study also confirmed these findings that personal BJW significantly predicts the life satisfaction than general BJW [24]. A research concluded that personal belief in just world predicts positive life satisfaction than a general belief in just world [5]. Another study suggested that personal BJW was negatively associated with distress and depression [25].

Fatima suggested that participants who are high on personal BJW are more satisfied and less distress in stressful situations [26]. Dalbert and Braun carried out a study and found out that individuals with high personal BJW have low levels of depression and overall better mood in distressing situations as compared with low personal BJW [27]. Findings described that personal BJW is negatively related to depression, anxiety, and stress in threatening situations [4]. Similarly, Dzuka and Dalbert described that participants who experience violence as stress, but their personal BJW is low they experienced more negative emotions as compared with high personal BJW [28].

The following study was conducted to investigate the role of personal and general belief in just world in developing psychological problems among hermaphrodites in Punjab.

\section{Research Methods}

\subsection{Hypothesis}

Based on the previous studies, following hypotheses are formulated:

1. Personal Believe in just world will negatively predict depression, anxiety, and stress among hermaphrodites.

2. The general belief in just world will positively predict 
depression, anxiety, and stress among hermaphrodites

\subsection{Participants}

The sample of the study was comprised of hermaphrodites $(\mathrm{N}=153$ ), Gurus (most senior member of community) $13.7 \%$ $(\mathrm{n}=21)$ and Chelas (younger members of community) $86.3 \%$ $(\mathrm{n}=132)$ age range from $16-81(M=36.84, S D=15.71)$. The sample was collected from twenty-one cities of Pakistan, Sample was selected through snowball sampling data collection. The following inclusion criteria were used for inclusion in the research sample: hermaphrodites, living within communities of transgender and willingness to participate in the current research project with or without money. Eunuch, crossdressers and individual living with their families were excluded from research sample

Table 1. Demographic characteristics of sample.

\begin{tabular}{llll}
\hline $\begin{array}{l}\text { Characteristic } \\
(\text { Age })\end{array}$ & $\begin{array}{l}\text { Gurus }(\mathbf{2 1 )} \% \\
(\boldsymbol{f})\end{array}$ & $\begin{array}{l}\text { Chelas }(\mathbf{1 3 2}) \% \\
(\boldsymbol{f})\end{array}$ & $\begin{array}{l}\text { Total } \\
(\mathbf{1 5 3}) \%(f)\end{array}$ \\
\hline 16-25 Years & $0.0(0)$ & $31.8(42)$ & $27.5(42)$ \\
26-35 Years & $14.3(3)$ & $33.3(44)$ & $30.7(47)$ \\
36-50 Years & $9.5(2)$ & $25.0(33)$ & $22.9(35)$ \\
51-81 Years & $76.2(16)$ & $9.8(13)$ & $19.0(29)$ \\
\hline
\end{tabular}

Table 1 depicts frequency and percentage of age characteristics of the sample with respect to groups according to their designation as Gurus and Chelas.

In this table, frequency of sample are Gurus $(f=21,13.7 \%)$ and Chelas $(f=135,86.3 \%)$. In the present study gurus and Chelas's further categorization are based on their age in four groups as 16-25 Years age, 26-35 Years age, 36-50 Years age and 51-81 Years age.

\subsection{Instruments}

For assessing perceived discrimination, depression, anxiety, stress, personal and general BJW following instruments were used for data collection:

\subsubsection{Depression, Anxiety, Stress Scale}

To measure depression, anxiety and stress: developed by Lovibond and Lovibond, the short and Urdu translated version [29] of Depression, Anxiety, and Stress Scale (DASS) [5] were used. There are three Subscales Depression, Anxiety, and Stress. Each scale has 7 items. Depression subscale consisted of item no $3,5,10,13,16,17$ and 21 , anxiety subscale consisted of item no 2, 4, 7, 9, 15, 19 and 20 and stress subscale consisted of item no $1,6,8,11,12,14$ and 18 . The scale is 4-point Likert ranging from 0 (did not apply to me at all), 1 (applied to me sometimes), 2 (applied to me most of the time) and to 3 (applied to me always). The scale measures negative feelings related to depression, anxiety, and stress. This scale only identifies the presence of psychological problems but does not give the diagnostic criteria. The internal consistency of this scale was (alphas) of 0.81-0.91 as reported by the original author and test-retest reliabilities of is $0.71-0.81$ by the original author.

\subsubsection{Personal BJW Scale}

The Personal BJW Scale developed by Dalbert and translated in Urdu by Fatima, and Khalid [30] was used to measure personal BJW. The scale has total 7 items and response format of 4 point rating ranging from 1 (strongly disagree), 2 (disagree), 3 (agree) and (strongly agree). Total score ranges from 7 to 28 indicating lower to high personal BJW. Internal reliability, reported by the original author $\alpha=.82$ to $\alpha=.87$ and of the Urdu version of Personal BJW was reported to be .93 and scale has discriminating validity by the translator [2].

\subsubsection{General BJW}

General BJW was assessed by using Scales of Belief in Immanent and Ultimate Justice: developed by Maes [31] translated by Fatima and Suhail [32]. The Scale of General BJW has 9 items and response format of the scale was 4 point rating ranging from 1 (strongly disagree), 2 (disagree), 3 (agree) and (strongly agree). Total score ranges from 9 to 36 indicating lower to high general belief in just world. Alpha reliability of general belief in just world is reported as $\alpha=.84$ by the original author.

\subsection{Research Design}

The present study is a cross-sectional research aimed to check the link between belief in just world and psychological problems.

\subsection{Procedure}

After ensuring the suitability of the instruments for the current study, a sampling plan was checked out to ensure the representativeness of the sample. After that, data were collected by approaching the communities of hermaphrodites. The purpose of the study was clearly communicated to the heads of specified communities. After obtaining the permit, individuals were personally approached. Clear instructions were given to all the participants about the instruments and response format, a written booklet of the questionnaires was provided to the participants and participants who have reading difficulty or could not read that questionnaire were interviewed and after interview questionnaires were marked according to theirs. Data collection was completed in 6 months. The obtained data were subjected to statistical analyses. The participants were debriefed about the objectives and the reason for the study. The rapport was established and participants were assured that the confidentiality of their personal information would be maintained and information will be used for research purpose only.

\section{Results}

The basic aim of the present research was to study the belief in just world as a predictor of psychological problems such as depression, anxiety, and stress among transgender in Punjab. After the completion of data collection, t-test, correlation, and stepwise regression were used for statistical analysis. 
Table 2. Relationship between Variables of Study among Hermaphrodites.

\begin{tabular}{llllll}
\hline Variables & PBJWS & GBJWS & DS & AS & SS \\
\hline PBJWS & - & $-.76^{* * *}$ & $-.33^{* * *}$ & $-.28^{* * *}$ & $-.33^{* * *}$ \\
GBJWS & & - & $.27^{* * *}$ & $.36^{* * *}$ & $.25^{* * *}$ \\
DS & & & - & $.01^{*}$ & $.19^{*}$ \\
AS & & & & - & $.04^{*}$ \\
SS & & & & & - \\
M & 14.23 & 27.57 & 12.89 & 12.44 & 12.63 \\
SD & 5.29 & 5.33 & 4.24 & 4.72 & 4.09 \\
$\alpha$ & .92 & .85 & .73 & .81 & .73 \\
\hline
\end{tabular}

Note PBJWS $=$ personal belief in a just world scale; GBJWS $=$ general belief in just world scale; $\mathrm{DD}=$ depression scale; $\mathrm{AS}=$ anxiety scale and $\mathrm{SS}=$ stress scales.

$* * * p<.001 . * p<.05$.

Table 2 shows mean standard deviations and internal satisfactory indices (alpha coefficients) of all the scales that used in the present study. The reliability analysis revealed that reliability coefficients for Personal BJW Scale, General BJW Scale, Depression Scale, Anxiety Scale and Stress Scales were found $.92, .85, .73, .81$ and .73 respectively, which indicates satisfactory internal consistency. In table 1 Pearson product moment correlations were calculated to see how the variables of the study were related in the sample of hermaphrodites. The table displays the correlation between the variable of study. The finding indicates that personal BJW was significantly correlated with depression, anxiety, and stress. The result of personal BJW is significant and negatively correlated with depression, anxiety and stress at 0.001 levels $(* * * p<.001)$. The finding indicates that general BJW was significantly correlated with depression, anxiety, and stress. The result of general BJW is significant and positively correlated with depression, anxiety and stress, at 0.001 levels $(* * * p<.001)$.

Table 3. Stepwise Regressions Predicting Depression from Belief in Just World Subscales (Personal BJW and General BJW) among Hermaphrodites.

\begin{tabular}{llll}
\hline Model & $\boldsymbol{B}$ & $\Delta \boldsymbol{R}^{2}$ & $\boldsymbol{F}$ \\
\hline Step 1 $\left(\mathrm{R}=.25, \mathrm{R}^{2}=.08\right)$ & & & \\
Personal BJW & $-.27^{* *}$ & .07 & $12.22^{* *}$ \\
Step 2 (R =.37, $\left.\mathrm{R}^{2}=.14\right)$ & & & \\
Personal BJW & $-.26^{* *}$ & .13 & $11.83^{* * *}$ \\
General BJW & $.25^{* *}$ & & \\
\hline
\end{tabular}

$* * * \mathrm{p}<.001 . * * \mathrm{p}<.01$

Table 3 shows the results of step-wise Regression showing the predicting depression from subscales of BJW as personal BJW and general BJW. Step 1 indicates personal BJW predict the significant depression as the $R^{2}$ value of .08 indicates $8 \%$ variance in the depression. The finding indicates that personal BJW has a significant negative effect on depression $\left(\beta=-.27,{ }^{* *} p<.01\right)$. Step 2 indicates the effect of both subscales personal BJW and general BJW as the $R^{2}$ value of .13 indicates $15 \%$ variance in the depression. The finding indicates that personal BJW and general BJW has significant effect on depression $(\beta=.25, * * p<.01)$.
Table 4. Stepwise Regressions Predicting Anxiety from Belief in Just World Subscales (Personal BJW and General BJW) among Hermaphrodites.

\begin{tabular}{llll}
\hline Model & $\boldsymbol{B}$ & $\Delta \boldsymbol{R}^{2}$ & $\boldsymbol{F}$ \\
\hline Step 1 $\left(\mathrm{R}=.33, \mathrm{R}^{2}=.11\right)$ & & & \\
General BJW & $.33^{* * *}$ & .10 & $18.65^{* * *}$ \\
Step 2 $\left(\mathrm{R}=.42, \mathrm{R}^{2}=.18\right)$ & & & \\
General BJW & $.32^{* * *}$ & .17 & $16.27 * * *$ \\
Personal BJW & $-.26^{* * *}$ & & \\
\hline
\end{tabular}

$* * * \mathrm{p}<.001$

Table 4 shows the results of step-wise Regression showing the predicting anxiety from subscales of belief in just world as personal BJW and general BJW. Step 1 indicates general BJW predict the significant anxiety as the $R^{2}$ value of .11 indicates $11 \%$ variation in the anxiety. The finding indicates that general BJW has a significant effect on anxiety $(\beta=.33$, $* * * p<.001)$. Step 2 indicates the effect of both subscales personal BJW and general BJW as the $R^{2}$ value of .18 indicates $18 \%$ variation in the anxiety. The finding indicates that personal $\mathrm{BJW}$ and general $\mathrm{BJW}$ has a significant negative effect on anxiety $(\beta=-.26, * * * p<.001)$.

Table 5. Stepwise Regressions Predicting Stress from Belief in Just World Subscales (Personal BJW and General BJW) among Hermaphrodites.

\begin{tabular}{llll}
\hline Model & $\boldsymbol{B}$ & $\Delta \boldsymbol{R}^{2}$ & $\boldsymbol{F}$ \\
\hline Step 1 $\left(\mathrm{R}=.36, \mathrm{R}^{2}=.13\right)$ & & & \\
Personal BJW & $-.36^{* * *}$ & .12 & $21.77^{* * *}$ \\
Step 2 $\left(\mathrm{R}=.42, \mathrm{R}^{2}=.18\right)$ & & & \\
Personal BJW & $-.35^{* * *}$ & .17 & $16.38^{* * *}$ \\
General BJW & $.23^{* *}$ & .17 & \\
\hline
\end{tabular}

$* * * \mathrm{p}<.001$.

Table 5 shows the results of step-wise Regression showing the predicting stress from subscales of belief in just world as personal BJW and general BJW. Step 1 indicates personal BJW predict the significant stress as the $R^{2}$ value of .13 indicates $13 \%$ variance in the stress. The finding indicates that personal BJW has a significant negative effect on stress $(\beta=-.36, * * * p<.001)$. Step 2 indicates the effect of both subscales personal BJW and general BJW as the $R^{2}$ value of .18 indicates $18 \%$ variance in the stress. The finding indicates that personal BJW and general BJW has a significant effect on stress $(\beta=.23, * * p<.01)$.

\section{Discussion}

The present study was aimed to examine the association between perception of discrimination and mental health; depression, anxiety and stress, the role of beliefs in a just world and coping strategies among hermaphrodites. Overall findings suggested that the perceived discrimination predicts depression, anxiety and stress, and belief in just world provide as a source for the hermaphrodites. The stronger the hermaphrodites believed in ones just world more they were contented with their lives, the improved frame of mind, reduced amount of depressive sign they exposed and the less nervous they were either perceived discrimination is high or low.

The present study was carried out to find out the 
relationship between perceived discrimination and mental health variables, I. e. Depression, anxiety, stress and loneliness. The first hypothesis was accepted as perceived discrimination has a positive significant correlation with depression. Findings indicate inter-scale correlation revealed that perception of discrimination and depression has a significant relationship (see table 2).

\subsection{Personal Believe in Just World will Negatively Predict Depression, Anxiety and Stress Among Hermaphrodites}

In the present study, a hypothesis that personal belief in just world will negatively predict mental health variables as depression, stress and anxiety among hermaphrodites was accepted as analysis shows significant positive correlation of personal belief in just world with depression, anxiety and stress (see tables 2, 3, $4 \& 5$ ). These results are consistent with the results of previous findings as it was demonstrated by research findings personal BJW was negatively associated with depression, anxiety and stress [4]. Cubela and Kvartuc described belief in just world for self is more related with adjustment in case of a harmful condition as compared with general belief in just world as personal belief in just world was more strongly related to mental wellbeing, personal belief in just world is helpful in reducing negative symptom related to mental health [33]. Furthermore, personal BJW was positively connected with positive affect and negatively with negative affect. These results were in line with our studies [34]. Strong belief in just world has positive relationship with positive trait and decrease in case of negative situations [35].

\subsection{The General Belief in Just World Will Positively Predict Depression, Anxiety and Stress Among Hermaphrodites}

In the present study, it was hypothesized that general belief in just world will positively predict mental health; depression, stress and anxiety among hermaphrodites. This hypothesis was accepted as analysis shows a significant positive correlation of personal belief in just world with depression, anxiety, and stress (see tables 2, 3, $4 \& 5$ ). These results are consistent with findings of the previous study in which Dalbert found that there is an affirmative link between depression and general belief in just world [18]. Lupfer, Doan, and Houstan also described that individuals reporting high belief in just world for others are more distressed and evaluate the negative unfair situation in daily life, and didn't attribute the situation positively [36]. Inline study with our findings described as general belief in just world has positive relation with negative emotions, as high belief in just world about general world minimize the effect of negative experiences [37]. Dalbert demonstrated results that jobless individual those who are high on general beliefs in just world reported more negative consequences and they could not find a reason for illogical threats [16].

\section{Conclusion and Implications of Study}

The research is most valuable because it was first one in which problems of hermaphrodites was explored with the relevance of belief in just world with psychological problems in Punjab's context where is lack of research among hermaphrodites. Within the clinical setting, therefore, it is vital that the belief in just world in hermaphrodites individual is encouraged to re-evaluate the areas of their life they wish to preserve according to their traditional cultural norms or because of an individualized preference, thus allowing a cultural continuity sense and hold over one's identity. As part of ongoing personal and general belief in just world growth, they should be encouraged to readjust other aspects of life as they see fit, whilst becoming part of the mainstream society.

\section{Limitations of Study and Suggestions}

Certain issues that could not be controlled can weaken the results of the study. A brief discussion of all these is mentioned here and further, some suggestions are recommended: The most important restriction of the study was the use of cross-sectional design and the study only found out the relationship of variables, so in order to investigate the causal relationship and strength of relationship longitudinal and experimental research design is suggested. There are substantial troubles inherent in the study of hermaphrodite's populations. Recognizing hermaphrodite's individuals and compliant transgender sub-groups in surveys can be complicated, so comparative research is needed to sample of hermaphrodites, individual having gender identity disorder, a eunuch, and cross-dressers.

\section{References}

[1] Lerner M J. The belief in a just world: A fundamental delusion. New York: Plenum Press, 1980.

[2] Dalbert C. The world is more just for me than generally: About the Personal Belief in a Just World Scale's validity [J]. Social Justice Research, 1999, 12, 79-98.

[3] Dzuka J, Dalbert C. Mental health and personality of Slovak unemployed adolescents: The impact of belief in a just world [J]. Journal of Applied Social Psychology, 2002, 32, 732-757.

[4] Otto K, Boos A, Dalbert C, Schops, Hoyer J. Post-traumatic symptoms, depression, and anxiety of flood victims: The impact of the belief in a just world [J]. Personality and Individual Differences, 2006, 40, 1075-1084.

[5] Sutton R M, Douglas K M. Justice for all, or just for me? More evidence of the importance of the self-other distinction in just-world beliefs [J]. Personality and Individual Differences, 2005, 39, 637-645.

[6] Lovibond P F, Lovibond S H. The structure of negative emotional states: Comparison of the Depression Anxiety Stress Scales (DASS) with the Beck Depression and Anxiety Inventories [J]. Behavior Research and Therapy, 1995, 33 (3), 335-343.

[7] American Psychiatric Association. Washington DC: American Psychiatric Association Publishing, Inc, 2001. 
[8] Seligman M E P, Walker E, Rosenhan D L. Abnormal psychology. ( $4^{\text {th }}$ ed.), New York: W. W. Norton \& Company, Inc, 2001.

[9] Ohman A. Fear and anxiety: evolutionary, cognitive and clinical perspectives. In M Leiwis, J M Havilland-Jones (Eds.). Handbook of Emotions. New York: The Guilford Press, 2000, 573-593.

[10] Barlow, David H. unrevealing the mysteries of anxiety and its disorders from the perspective of emotion theory [J]. American Psychologist, 2002, 6, 1247-1263.

[11] Hintze J. Intervention for fear and anxiety problems. In M. Shim, H. M. Walker \& G. Stoner (Eds.), Intervention for Academic and Behavior Problems: Perspective and Remedial Approaches, 2002, 939-960). Bethesda: National Association of School Psychologist.

[12] Cohen S, Kessler R C, Gordon U L. Strategies for measuring stress in studies of the psychiatric and physical disorder. In: S. Cohen, R. C. Kessler, \& U. L. Gordon, (eds.) Measuring Stress: A Guide for Health and Social Scientists. New York, NY: Oxford University Press; 1995, 3-26.

[13] McEwen B S. Protective and damaging effects of stress mediators [J]. New England Journal Medicine, 1998, 338 (3), 171-179.

[14] Thapa S, Hauff E. Psychological Distress among displaced person during an armed conflict in Nepal [J]. Social Psychiatry Epidemiology, 2005, 40, 672-679.

[15] Ritter C, Benson D E, Snyder C. Belief in a just world and depression [J]. Sociological Perspectives, 1990, 33, 235-252.

[16] Dalbert C. The justice motive as a personal resource: Dealing with challenges and critical life events, 2001, New York: Plenum Press.

[17] Brown J, Grover J. The role of moderating variables between stressor exposure and being distresses in a sample of serving police officers [J]. Personality and Individual Differences, 1998, 24, 181-185.

[18] Dalbert C. Belief in a just world, well-being, and coping with an unjust fate. In L. Montada, \& M. J. Lerner (Eds.), Responses to victimizations and belief in a just world, 1998, 87-105. New York: Plenum Press.

[19] Benson D E, Ritter C. Belief in a just world, job loss, and depression [J]. Sociological Focus, 1990, 23, 49-63.

[20] Cheung C, Kwok S. Conservative orientation as a determinant of hopelessness [J]. Journal of Social Psychology, 1996, 36, 333-347.

[21] Correia I, Batista M T, Lima M L. Does the belief in a just world bring happiness? Causal relationships among belief in a just world, life satisfaction and mood [J]. Australian Journal of Psychology, in press.

[22] Dalbert C. Beliefs in a just world as a buffer against anger [J]. Social Justice Research, 2002, 15, 123-145.
[23] Lipkus I M, Dalbert C, Siegler I C. The importance of distinguishing the belief in a just world for self versus for others: Implications for psychological well-being [J]. Personality and Social Psychology Bulletin, 1996, 22, 666-677.

[24] Cubela V, Prorokovic A, Gregov L. Neki tipovi valjanosti i pouzdanosti dviju skala vjerovanja u pravedan svijet, Radovi Filozofskog fakulteta u Zadru, 1999, 38, 133-148.

[25] Kamble S V, Dalbert C. Belief in a just world and well being. Paper presented at the 12th Biennial Conference of International Society for Justice Research, 2008, Adelaide, Australia.

[26] Fatima I. Beliefs in a just world and psychological well being. Unpublished M. Phil thesis, 2004, University of Punjab, Pakistan.

[27] Dalbert C, Braun A. Coping with cancer: A study with adult cancer patients. University of Tubingen, 1997, Unpublished data.

[28] Dzuka J, Dalbert C. Student violence against teachers: Teachers' well-being and the belief in a just world [J]. European Psychologist, 2007, 12, 253-260.

[29] Aslam N. Psychological disorder and resilience among earthquake affected individuals. Unpublished M. Phil Dissertation, National Institute of psychology, Quaid-i- Azam University, Islamabad, Pakistan, 2007.

[30] Fatima I, Khalid R. Some aspects of reliability and validity of Beliefs in a Just World Questionnaire [J]. Pakistan Journal of Social and Clinical Psychology, 2007, 5, 15-24.

[31] Maes J. Immanent justice and ultimate justice: two ways of believing in justice. In L Montada, M J Lerner (Eds.), Responses to victimizations and belief in a just world, 1998, 9-40. New York: Plenum Press.

[32] Fatima I, Suhail K. Belief in a just world and subjective well-being: Mothers of normal and Down syndrome children [J]. International Journal of Psychology, 2010, 45, 461-468.

[33] Cubela V, Kvartuc T. Effects of mobbing on justice beliefs and adjustment [J]. European Psychologist, 2007 12, 261-271.

[34] Donat, M., Peter, F., Dalbert, C., and Kamble, S. V. (2016). The meaning of students' personal belief in a just world for positive and negative aspects of school-specific well-being. Social Justice Research, 29, 73-102.

[35] Donat, M., Wolgast, A., and Dalbert, C. (2018). Belief in a just world as a resource of victimized students. Social Justice Research, 31, 133-151.

[36] Lupfer M B, Doan K, Houston D A. Explaining unfair and fair outcomes: The therapeutic value of attributional analysis [J]. British Journal of Social Psychology, 1998, 37, 495-511.

[37] Dalbert, C., and Donat, M. (2015). "Belief in a just world," in International Encyclopedia of the Social and Behavioral Sciences, 2nd Edn, Vol. 2, ed. J. D. Wright (Oxford: Elsevier), 487-492. 